\title{
COMPOSIÇÃO FLORÍSTICA DE UMA FLORESTA ESTACIONAL SEMIDECIDUAL MONTANA NO MUNICÍPIO DE VIÇOSA-MG ${ }^{1}$
}

\author{
João Augusto Alves Meira-Neto² e Fernando Roberto Martins ${ }^{3}$
}

\begin{abstract}
RESUMO - O objetivo do presente estudo foi investigar a composição florística arbórea da Mata da Silvicultura (204' S e 42 $55^{\circ}$ W), município de Viçosa, Zona da Mata de Minas Gerais, com o intuito de avaliar sua similaridade com outras florestas. Para comparação florística foi utilizada a análise de agrupamentos pelo método de médias aritméticas não-ponderadas (UPGMA), a partir dos índices binários de similaridade de Sørensen entre as florestas comparadas. Foram relacionadas 154 espécies de 47 famílias botânicas para a Mata da Silvicultura. Esta mata mostrou-se mais similar às florestas semideciduais de altitude de Lavras (MG) e de Atibaia (SP) e menos similar às florestas submontanas e litorâneas. Estes resultados evidenciam uma importante influência das temperaturas na determinação do tipo florístico das florestas do Sudeste e Sul brasileiros.
\end{abstract}

Palavras-chave: Composição florística e Florestas Estacionais Semideciduais.

\section{FLORISTIC COMPOSITION OF A MONTANE SEASONAL SEMIDECIDUOUS TROPICAL FOREST IN VIÇOSA, MG, BRASIL}

\begin{abstract}
This study aims to investigate the floristic composition of the Silvicultura forest (20 45 'S and $42^{\circ} 55^{\prime} \mathrm{W}$ ) by comparing it to other forest compositions. Thus, the cluster analysis method of unweighted pairgroup using arithmetic averages (UPGMA) was used, applying the Sørensen binary similarity index found among compared forests. A list of 154 species of 47 families was recorded. The Silvicultura forest is more similar to the montane semideciduous forests of Lavras and Atibaia, but less similar to submontane and coastal forests. These results show that temperature plays an important role in the floristic differentiation of the southern and southeastern Brazilian forest types.
\end{abstract}

Key words: $\quad$ Floristic composition, seasonal tropical forest.

\section{INTRODUÇÃO}

Ainda são pouco difundidas as informações disponíveis a respeito da composição florística das florestas estacionais semideciduais, aluviais, montanas ou submontanas na Zona da Mata de Minas Gerais. Embora haja um número considerável de teses e monografias que abordem este assunto, são poucos os artigos publicados em periódicos (Meira-Neto et al., 1997a, b, c, 1998; Almeida \& Souza, 1997).
As composições dessas florestas da Zona da Mata têm sido analisadas, nesses artigos, num contexto regional, o que torna interessante a inserção de suas composições em abordagem mais ampla. Um aspecto ao qual se tem dado ênfase em estudos de comparação da composição é o florístico-comparativo. As composições florísticas de diferentes trechos de vegetação podem ser simplesmente confrontadas (Meira-Neto et al., 1989; Oliveira Filho \& Machado, 1993), podem ser relacionadas por meio de análise de agrupamentos (Torres, 1989;

1 Recebido para publicação em 2.5.2001.

Aceito para publicação em 20.6.2002.

Parte da tese apresentada pelo primeiro autor ao Curso de Doutorado em Ciências Biológicas da UNICAMP.

2 Departamento de Biologia Vegetal da Universidade Federal de Viçosa - UFV. Bolsista CAPES e CNPq, 36571-000 ViçosaMG, <j.meira@mail.ufv.br>. ${ }^{3}$ Departamento de Botânica da Universidade Estadual de Campinas - UNICAMP, Caixa Postal 6109, 13083-970 Campinas-SP, <fmartins@unicamp.br>. 
Silva, 1989; Salis, 1990; Siqueira, 1994; Oliveira-Filho, et al. 1994) e podem até ser ordenadas por métodos estatísticos multivariados (Siqueira, 1994; Oliveira-Filho et al., 1994). Tais métodos permitem a visualização da proximidade florística entre diferentes tipos florestais, o que é útil ao entendimento da fitogeografia florestal brasileira. Até discriminações tênues entre diferentes tipos florestais podem ser feitas, como a distinção das florestas estacionais semideciduais montanas e submontanas (Meira-Neto et al., 1989; Oliveira-Filho \& Machado, 1993; Torres et al., no prelo). A utilização desses métodos florístico-comparativos permite estabelecer a identidade fitogeográfica de uma certa comunidade florestal ao confrontar suas semelhanças e diferenças de composição com as de florestas de outras regiões, identificando quais são as espécies mais importantes nessas comparações e quais são os possíveis fatores determinantes dessas variações.

O objetivo do presente estudo foi investigar a composição florística das árvores da Mata da Silvicultura, com o intuito de compará-la com outras florestas do Sudeste e Sul brasileiros, lançando mão de diferentes metodologias para o melhor entendimento desse conjunto de componentes de um ecossistema florestal tropical.

\section{MATERIAL E MÉTODOS}

\section{1. Área de Estudos}

O município de Viçosa situa-se nas coordenadas $20^{\circ} 45^{\prime} \mathrm{S}$ e $42^{\mathrm{O}} 55^{\prime} \mathrm{W}$, perifericamente no norte da Zona da Mata, sendo entrecortado por rios e córregos tributários do rio Doce (Mariscal-Flores, 1993; Valverde, 1958). $\mathrm{O}$ centro da cidade de Viçosa tem altitude de $650 \mathrm{~m}$, mas são encontradas altitudes maiores que $800 \mathrm{~m}$ nos topos dos muitos morros do município (Comissão Geográfica e Geológica de Minas Gerais, 1930). O clima é tropical de altitude com verões chuvosos e invernos frios e secos, do tipo Cwb pelo sistema de Köppen (Golfari, 1975; Valverde, 1958; Departamento Nacional de Meteorologia, 1992). A precipitação média anual é de 1221,4 mm (Departamento Nacional de Meteorologia, 1992).

A Mata da Silvicultura, local onde foi realizado este estudo, situa-se em altitudes entre 670 e $730 \mathrm{~m}$ e é um fragmento florestal de 17 ha, resultante de regeneração natural. Foi adquirida pela Universidade Federal de Viçosa em 1936 e, desde então, encontra-se protegida de cortes e extração de madeira (Mariscal-Flores, 1993),

R. Árvore, Viçosa-MG, v.26, n.4, p.437-446, 2002 o que tem garantido a manutenção do adiantado estádio sucessional, que conta atualmente com mais de 60 anos. Alguns talhões silviculturais de espécies nativas e introduzidas encontram-se a oeste desse fragmento florestal. Esses talhões, quando em contato direto com o núcleo do fragmento, tendem a ser ocupados pelas espécies nativas da mata, com o passar dos anos. Alguns indivíduos dessas espécies introduzidas podem, também, ser encontrados no núcleo do fragmento

\subsection{Composição Florística}

O levantamento florístico relacionou, em 1 ha de amostra fitossociológica, com unidades amostrais de 10 x $10 \mathrm{~m}$, reunidas em parcelas de 20 × $50 \mathrm{~m}$, todas as espécies arbóreas amostradas que tivessem indivíduos com circunferência do tronco, a 1,3 m de altura do solo, igual ou maior que $10 \mathrm{~cm}$ (Meira-Neto \& Martins, 2000). Cada espécie aparece com o número de coleta do material depositado no Herbário da Universidade Federal de Viçosa (VIC). As coletas foram feitas mediante a utilização de tesoura de alta poda no interior da área amostral.

A identificação taxonômica foi efetuada mediante consultas a herbários, consultas a especialistas e por meio da literatura. O sistema de classificação utilizado foi o de Cronquist (1988). Todos os nomes de espécies e suas sinonímias, com os respectivos autores, foram confirmados e atualizados pela literatura taxonômica.

A comparação da composição florística da Mata da Silvicultura foi feita com a de outras florestas, a maior parte delas do Sudeste brasileiro. Cada floresta comparada floristicamente à Mata da Silvicultura foi escolhida por pertencer a grupos diferentes na análise de agrupamentos feita por Oliveira-Filho et al. (1994), com o intuito de determinar qual desses grupos teria maior similaridade florística com a Mata da Silvicultura. Desta maneira, foram escolhidas para comparação as florestas de Lavras, a $925 \mathrm{~m}$ de altitude, MG (Oliveira-Filho et al., 1994); da Serra da Canastra, a 950 m, MG (Mota, 1984); Uberlândia, a 800 m, MG (Schiavini, 1992); Linhares, a 50 m, ES (Peixoto \& Gentry, 1990); Atibaia, a $1200 \mathrm{~m}$, SP (Meira-Neto et al., 1989); Moji-Guaçu, a 595 m, SP (Gibbs \& Leitão Filho, 1978); Ubatuba, a 105 m, SP (Silva \& Leitão Filho, 1982); Bauru, 570 m, SP (Cavassan et al., 1984); e Londrina, 700 m, PR (Soares-Silva \& Barroso, 1992). As espécies relacionadas nesses levantamentos tiveram seus binômios atualizados, para evitar sinonímias que influíssem nos índices de similaridade, 
por meio do "software" do índice de espécies do Royal Botanic Gardens of Kew (1993). As espécies indeterminadas foram consideradas como espécies diferentes entre si, mesmo quando pertencentes ao mesmo gênero. A partir da composição florística de cada uma dessas florestas foi feita uma matriz dos índices de similaridade de Sørensen (Brower \& Zar, 1984). A fórmula para o cálculo desse índice é:

$$
\mathrm{IS}=2 \mathrm{C} /(\mathrm{S} 1+\mathrm{S} 2)
$$

em que $\mathrm{C}=$ número de espécies em comum entre as duas florestas comparadas; $\mathrm{S} 1$ = número de espécies da floresta 1; e S2 = número de espécies da floresta 2.

Para interpretação das relações florísticas entre cada uma das florestas utilizou-se o método de agrupamentos pelas médias não-ponderadas (UPGMA), por meio do qual foi construído um dendrograma que expressa graficamente as relações de similaridades entre essas áreas (Sneath \& Sokal, 1973). A escolha dessa metodologia para análise de agrupamentos deveu-se ao fato ser a mesma utilizada por Oliveira-Filho et al. (1994), o que permite a comparação.

Pelo fato de a Mata da Silvicultura estar em altitudes próximas dos $750 \mathrm{~m}$, considerada limítrofe por Torres et al. (no prelo) para as florestas estacionais de altitude, ou montanas, do Estado de São Paulo, foi utilizada a lista de espécies indicadoras de florestas de altitude apresentada por Meira-Neto et al. (1989), para saber quantas das espécies em comum entre as florestas comparadas são indicadoras.

Foi realizada a análise do coeficiente $\left(\mathrm{r}_{\mathrm{s}}\right)$ de correlação por postos de Spearman (Siegel 1975), para testar a correspondência entre os valores do índice de similaridade de Sørensen entre a Mata da Silvicultura e as florestas comparadas, as altitudes das florestas comparadas e as distâncias entre a Mata da Silvicultura e as florestas comparadas.

\section{RESULTADOS E DISCUSSÃO}

Foram relacionadas 154 espécies arbóreas, pertencentes a 105 gêneros de 47 famílias botânicas (Quadro 1). Dessas espécies, sete tiveram sua identificação mais exclusiva em nível de gênero e uma em nível de família. Cinco permaneceram como morfoespécies sem identificação taxonômica mais exclusiva que a Classe Magnoliopsida (dicotiledôneas) e não foram relacionadas. As famílias mais representativas floristicamente foram Rubiaceae com 16 espécies, Leguminosae Papilionoideae com 11, Lauraceae e Leguminosae Mimosoideae com 10, Euphorbiaceae e Myrtaceae com 9, Annonaceae, Flacourtiaceae e Melastomataceae com 6. Os gêneros mais ricos foram Psychotria, com 6 espécies; Machaerium, Miconia e Ocotea, com 5; Casearia, Inga e Eugenia, com 4. A Mata da Silvicultura apresenta riqueza de espécies por famílias botânicas muito próxima àquela relatada por Leitão-Filho (1982) para as florestas estacionais semideciduais do interior do Estado de São Paulo, especialmente no que diz respeito à riqueza destacada das famílias Leguminosae Papilionoideae, Euphorbiaceae, Myrtaceae, Lauraceae e Rubiaceae. Confirma-se essa semelhança com o fato de as florestas de Atibaia (Meira-Neto et al., 1989), MojiGuaçu (Gibbs \& Leitão-Filho, 1978) e Bauru (Cavassan et al., 1984) mostrarem-se mais similares à Mata da Silvicultura que as de Ubatuba, SP (Silva \& Leitão-Filho, 1982) e Linhares, ES (Peixoto \& Gentry, 1990), que são florestas próximas à região litorânea (Quadro 2, Figura 1).

A Mata da Silvicultura é um fragmento florestal como a grande maioria dos remanescentes florestais da Zona da Mata de Minas Gerais, que apesar das pequenas dimensões em área (17 ha) tem composição florística rica em espécies. Volpato (1994) relacionou 95 espécies arbóreas, em amostra de $12.000 \mathrm{~m}^{2} \mathrm{em}$ um fragmento florestal de 194 ha, a Mata do Paraíso, também no município de Viçosa. Embora a metodologia aplicada não tenha sido a mesma deste trabalho, pode-se afirmar que a Mata da Silvicultura, com suas 154 espécies, possui uma composição florística muito representativa da flora arbórea regional, se contraposta à da Mata do Paraíso, que possui área mais de dez vezes maior, amostra maior e menor número de espécies arbóreas, segundo os estudos já realizados.

Pelos índices de similaridade de Sørensen (Quadro 2) e pelo dendrograma gerado pela análise de agrupamentos (Figura 1), verifica-se que a Mata da Silvicultura é mais similar às florestas de Lavras e de Atibaia, em um nível de ligação de $23 \%$. Similaridades menores foram as das florestas de Uberlândia, em um nível de ligação de 15,4\%, e da Serra da Canastra, $15 \%$. O aglomerado formado pelas florestas de Moji-Guaçu, Bauru e Londrina teve seu nível de ligação com o grupo constituído pelas cinco florestas anteriormente comentadas em torno de $11 \%$. As florestas de Ubatuba, ligada em nível de 6,5\%, e de Linhares, em nível de $3 \%$, foram as menos similares à Mata da Silvicultura.

R. Árvore, Viçosa-MG, v.26, n.4, p.437-446, 2002 
Quadro 1 - Lista florística das espécies arbóreas da Mata da Silvicultura, Viçosa-MG. Os números correspondem às coletas de J. A. A. Meira Neto, depositadas no Herbário da Universidade Federal de Viçosa (VIC)

Table 1 - Floristic list of tree species of the "Mata da Silvicultura", Viçosa, MG. J. A. A. Meira Neto collection data - VIC Herbarium

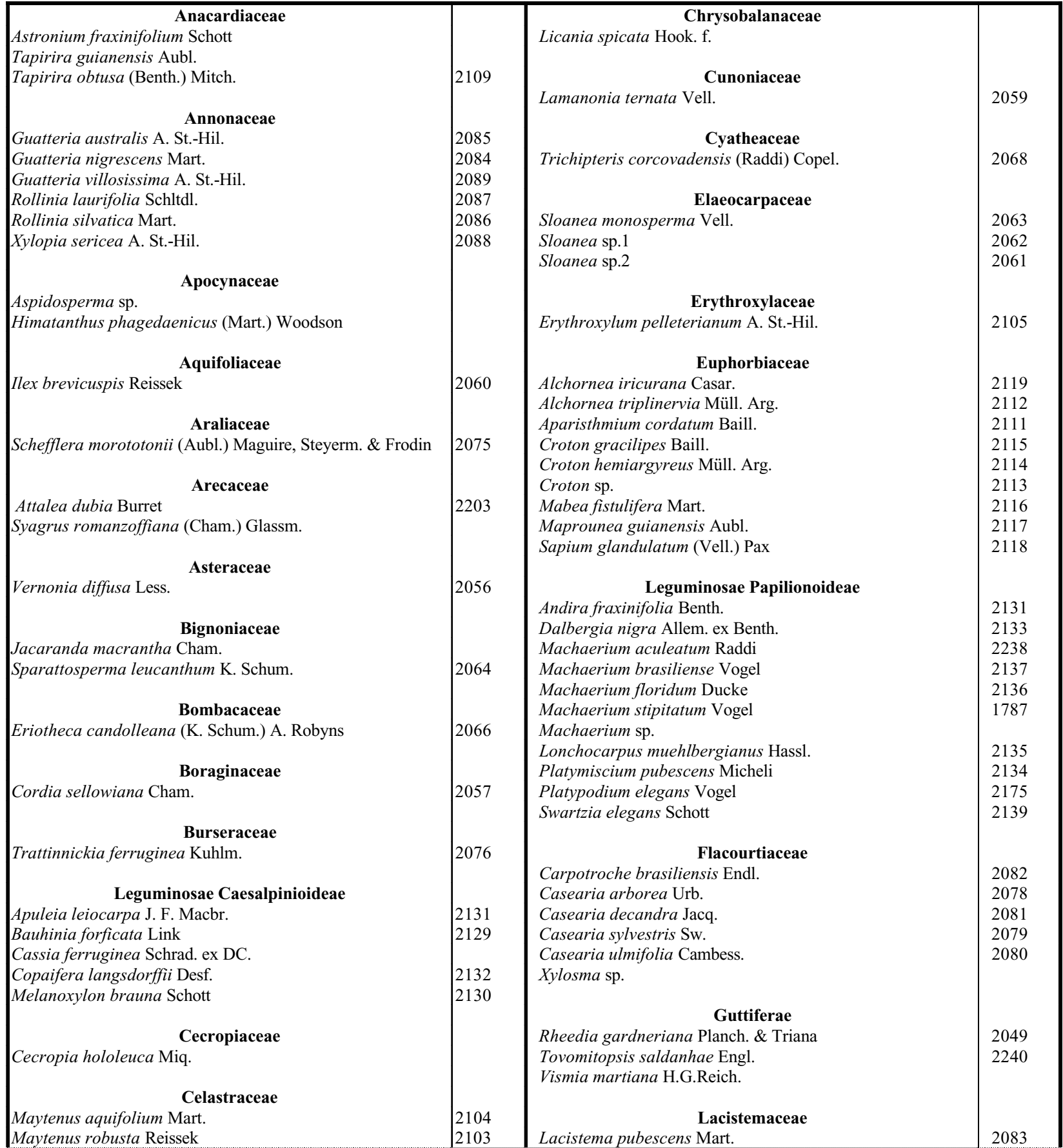

Continua...

Continued... 
Quadro 1, Cont.

Table 1, Cont.

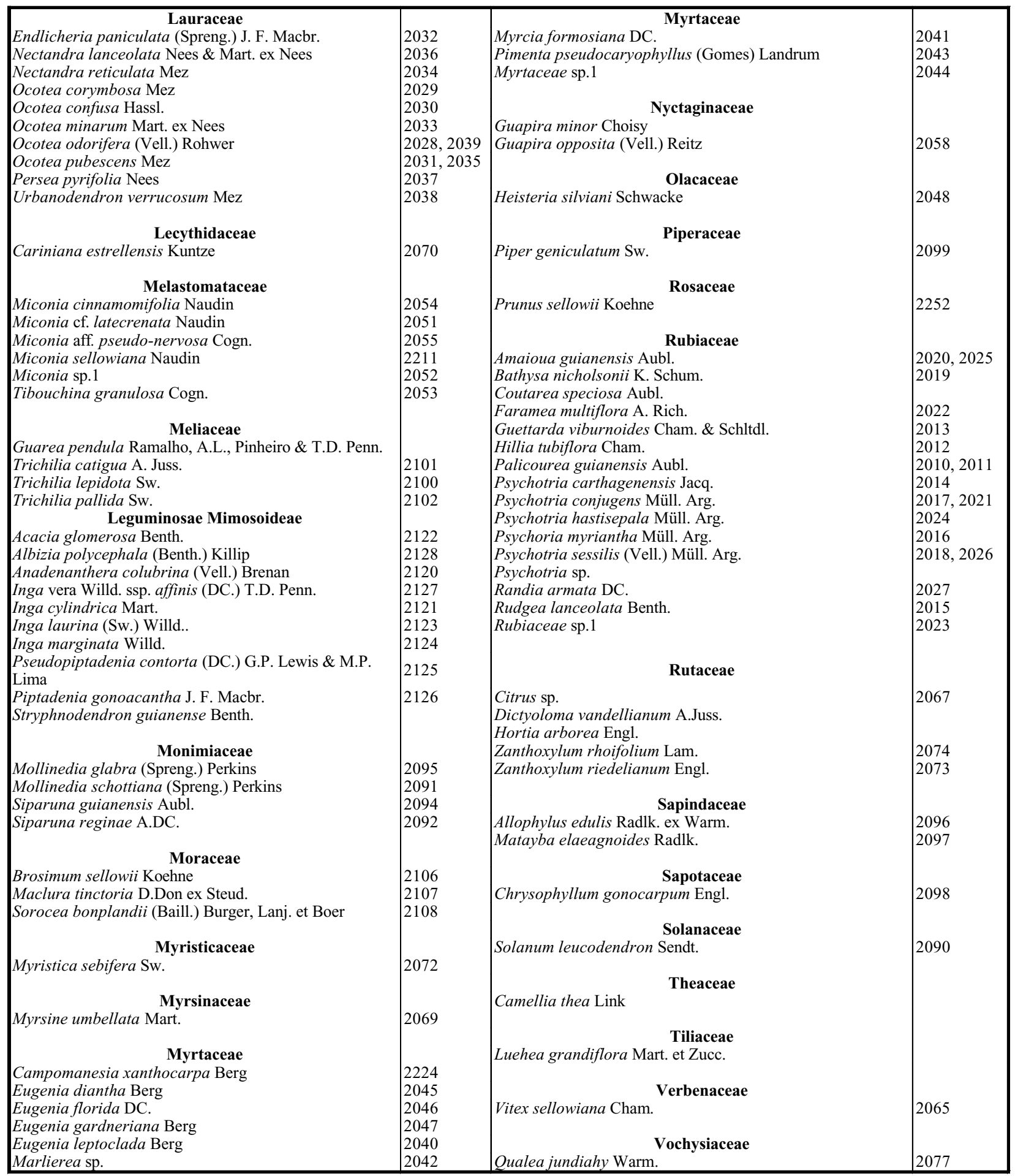


Quadro 2 - Similaridade florística (Sørensen binário) entre dez florestas do Sudeste e Sul do Brasil. Lavras (Oliveira-Filho et al., 1994), Moji-Guaçu (Gibbs \& Leitão-Filho, 1978), Bauru (Cavassan et al., 1984), Atibaia (Meira-Neto et al., 1989), Uberlândia (Schiavini, 1992), Linhares (Peixoto \& Gentry, 1990), Londrina (Soares-Silva \& Barroso, 1992), Viçosa (este trabalho), Canastra (Serra da Canastra, Mota, 1984), Ubatuba (Silva \& Leitão Filho, 1982)

Table 2 - Floristic similarity (binary Sørensen) of 10 southeastern and southern Brazilian forests. Lavras (Oliveira-Filho et al., 1994), Moji Guaçu (Gibbs \& Leitão-Filho, 1978), Bauru (Cavassan et al., 1984), Atibaia (Meira-Neto et al., 1989), Uberlândia (Schiavini, 1992), Linhares (Peixoto \& Gentry, 1990), Londrina (Soares-Silva \& Barroso, 1992), Viçosa (este trabalho), Canastra (Serra da Canastra, Mota, 1984), Ubatuba (Silva \& Leitão Filho, 1982)

\begin{tabular}{|c|c|c|c|c|c|c|c|c|c|c|}
\hline Lavras & 1 & & & & & & & & & \\
\hline Moji-Guaçu & 0,095 & 1 & & & & & & & & \\
\hline Bauru & 0,137 & 0,191 & 1 & & & & & & & \\
\hline Atibaia & 0,287 & 0,137 & 0,157 & 1 & & & & & & \\
\hline Uberlândia & 0,218 & 0,101 & 0,113 & 0,086 & 1 & & & & & \\
\hline Linhares & 0,033 & 0,032 & 0,016 & 0,020 & 0,036 & 1 & & & & \\
\hline Londrina & 0,125 & 0,116 & 0,232 & 0,148 & 0,101 & 0,049 & 1 & & & \\
\hline Viçosa & 0,229 & 0,077 & 0,106 & 0,220 & 0,160 & 0,046 & 0,154 & 1 & & \\
\hline Canastra & 0,183 & 0,090 & 0,115 & 0,147 & 0,151 & 0,012 & 0,071 & 0,121 & 1 & \\
\hline \multirow[t]{2}{*}{ Ubatuba } & 0,107 & 0,033 & 0,033 & 0,109 & 0,044 & 0,021 & 0,063 & 0,117 & 0,063 & 1 \\
\hline & Lavras & Moji-Guaçu & Bauru & Atibaia & Uberlândia & Linhares & Londrina & Viçosa & Canastra & Ubatuba \\
\hline
\end{tabular}

As espécies que a Mata da Silvicultura possui em comum com as florestas de Lavras e de Atibaia, que se mostraram mais similares entre si, são Alchornea triplinervia, Amaioua guianensis, Casearia decandra, Cordia sellowiana, Guapira opposita, Guatteria nigrescens, Lamanonia ternata, Machaerium brasiliense, Machaerium stipitatum, Ocotea corymbosa, Persea pyrifolia, Piptadenia gonoacantha, Myrsine umbellata e Sloanea monosperma, devendo ser ressaltado que, destas Alchornea triplinervia, Casearia decandra, Cordia sellowiana, Guatteria nigrescens, Lamanonia ternata, Myrsine umbellata e Sloanea monosperma foram relatadas como espécies indicadoras de florestas de altitude do Sul e Sudeste brasileiros (Meira-Neto et al., 1989). São sete as espécies indicadoras de florestas de altitude das 14 espécies em comum entre essas três florestas. Entre a Mata da Silvicultura e a floresta de Atibaia ocorrem 26 espécies em comum, oito das quais são espécies indicadoras de florestas de altitude sensu (MeiraNeto et al., 1989). Destas oito espécies indicadoras só Prunus sellowii não foi encontrada em Lavras. Entre a Mata da Silvicultura e a floresta de Lavras há 34 espécies em comum; destas, sete constam como espécies indicadoras de florestas de altitude. É digno de nota que das oito espécies indicadoras de florestas de altitude comuns às florestas de Viçosa e de Atibaia sete ocorreram também em Lavras, mostrando mais constância que as demais espécies nesse tipo florestal.

Foram encontradas 20 espécies em comum entre a Mata da Silvicultura e a reserva do Panga, em Uberlândia, das quais apenas Prunus sellowii e Myrsine umbellata são citadas como espécies indicadoras de florestas de altitude. Entre a Mata da Silvicultura e a Mata da Serra da Canastra foram encontradas 17 espécies em comum, e Alchornea triplinervia, Lamanonia ternata e Prunus sellowii foram as espécies indicadoras de florestas de altitude comuns às duas florestas.

O conjunto formado pelas florestas de Moji-Guaçu, Bauru e Londrina representa um tipo florestal que se situa em menores altitudes e possui menor número de espécies em comum com a Mata da Silvicultura. Foram encontradas 12 espécies em comum entre a Mata da Silvicultura e a floresta em Bauru, nenhuma delas sendo indicadora 
de florestas de altitude. Em comparação à floresta de Moji-Guaçu, das sete espécies em comum com a Mata da Silvicultura, apenas Alchornea triplinervia é indicadora de floresta de altitude. Ao comparar essa mata de Viçosa com a floresta de Londrina, a mais austral das florestas comparadas, constou-se que quatro das 18 espécies em comum são indicadoras de florestas de altitude, sendo elas Alchornea triplinervia, Casearia decandra, Myrsine umbellata e Sloanea monosperma. Dentre essas três florestas de menores altitudes, a de Londrina foi a mais similar à da Silvicultura (Quadro 2).

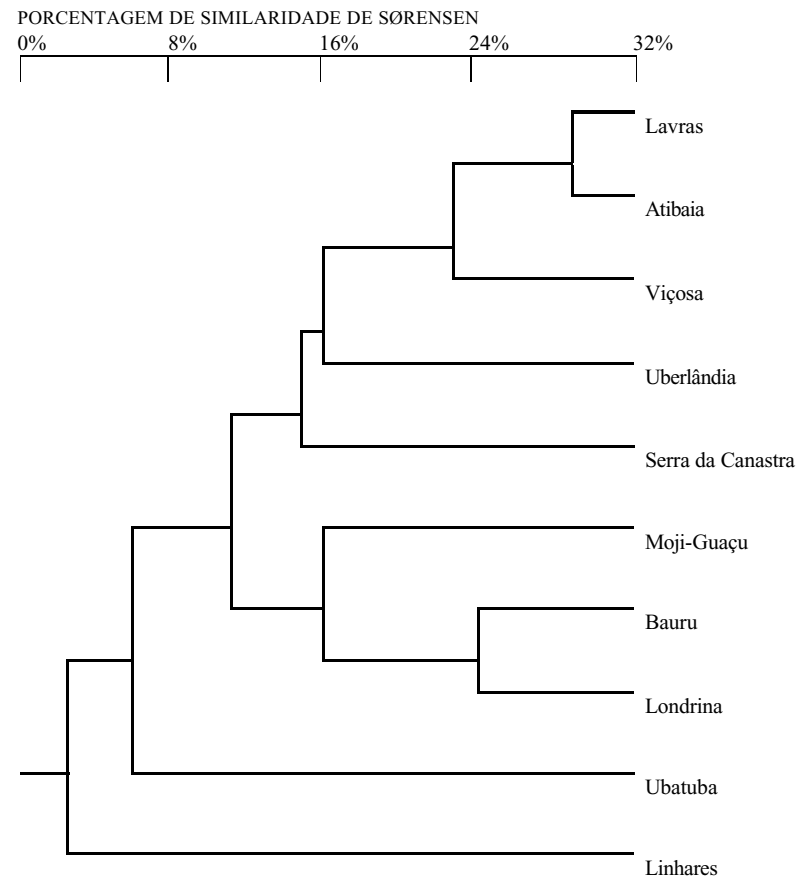

Figura 1 - Dendrograma da análise de agrupamentos por médias não-ponderadas (UPGMA) das similaridades florísticas (Sørensen) entre dez florestas do Sudeste e Sul do Brasil. Lavras (Oliveira-Filho et al., 1994), Atibaia (Meira-Neto et al., 1989), Viçosa (este trabalho), Uberlândia (Schiavini, 1992), Serra da Canastra (Mota, 1984), Moji-Guaçu (Gibbs \& Leitão-Filho, 1978), Bauru (Cavassan et al., 1984), Londrina (Soares-Silva \& Barroso, 1992), Ubatuba (Silva \& Leitão Filho, 1982), Linhares (Peixoto \& Gentry, 1990).

Figure 1 - Cluster anlysis dendrogram of unweighted pairgroup arithmetic average clustering method (UPGMA) of floristic similarity (binary Sørensen) of 10 southeastern and southern Brazilian forests. Lavras (Oliveira-Filho et al. 1994), Atibaia (Meira-Neto et al. 1989), Viçosa (this work), Uberlândia (Schiavini, 1992), Serra da Canastra (Mota, 1984), Moji Guaçu (Gibbs \& Leitão-Filho, 1978), Bauru (Cavassan et al. 1984), Londrina (Soares-Silva \& Barroso, 1992), Ubatuba (Silva \& Leitão Filho, 1982), Linhares (Peixoto \& Gentry, 1990).
As florestas de Ubatuba e de Linhares foram as mais dissimilares à Mata da Silvicultura e a todas as outras dessa comparação, inclusive entre si. Apenas quatro espécies são comuns entre a mata de Viçosa e a de Linhares, e nenhuma é indicadora de florestas de altitude. Houve maior número de espécies em comum entre a Mata da Silvicultura e a floresta de Ubatuba, devendo ressaltar que das 16 espécies comuns quatro são indicadoras de floresta de altitude: Cordia sellowiana, Guatteria nigrescens, Lamanonia ternata e Prunus sellowii.

Nenhuma das espécies indicadoras de florestas de altitude do sistema Mantiqueira (Oliveira-Filho \& Machado, 1993) foi encontrada na Mata da Silvicultura.

Nota-se que a Mata da Silvicultura, apesar de sua altitude estar pouco acima dos $650 \mathrm{~m}$, possui maior identidade florística com as florestas de altitude. Florestas submontanas também lhe são similares, mais que aquelas próximas da faixa costeira, que são essencialmente atlânticas. Dentre as duas florestas atlânticas, de Ubatuba e de Linhares, fica evidente a maior similaridade florística com a mais meridional, a de Ubatuba (Quadro 2).

A análise do coeficiente de correlação por postos de Spearman $\left(r_{s}\right)$ para testar a correspondência dos valores do índice de similaridade de Sørensen entre a Mata da Silvicultura e as florestas comparadas, assim como as altitudes dessas florestas, demonstrou que existe correlação entre maiores altitudes e maiores similaridades florísticas, pois foi encontrado $r_{\mathrm{s}}=0,8$ para $\mathrm{n}=9$, número considerado significativo em nível de $\alpha=0,01$. A mesma análise realizada para testar a correspondência entre os valores do índice de similaridade de Sørensen e as distâncias entre a Mata da Silvicultura e as florestas comparadas demonstrou que não existe correlação entre menores distâncias e maiores similaridades florísticas no estrato arbóreo, pois foi encontrado $r_{s}=0,004$ para $n=9$, número considerado não-significativo.

A maior similaridade da Mata da Silvicultura se deu com florestas estacionais semideciduais de altitude dos Estados de Minas Gerais e São Paulo, especificamente com a floresta de Lavras e a de Atibaia. Como a similaridade com uma floresta de Lavras foi um pouco maior que a de Atibaia (Quadro 2), ao analisar o dendrograma apresentado por Oliveira-Filho et al. (1994), para 30 florestas confrontadas floristicamente mediante análise de agrupamentos de mesma metodologia que a do presente trabalho, é possível identificar a maior relação florística da Mata da Silvicultura com as florestas de Madre de 
Deus de Minas, Poço Bonito, Tiradentes, Itutinga, Bom Sucesso e Lavras (Oliveira-Filho et al., 1994), todas de Minas Gerais. As florestas de Atibaia (Meira-Neto et al., 1989), São José dos Campos (Silva, 1989) e de Jundiaí (Rodrigues et al., 1989), no Estado de São Paulo, também são muito similares à Mata da Silvicultura. Se analisar do ponto de vista geográfico, nota-se que essas florestas estão na Serra da Mantiqueira, em seus contrafortes ou em regiões serranas próximas suficientemente para receber as influências florísticas dessa grande serra. Da mesma maneira, a maior dissimilaridade florística da Mata da Silvicultura foi com as florestas de Linhares e de Ubatuba. Por conseqüência, ao analisar o dendrograma apresentado por Oliveira-Filho et al. (1994), é possível afirmar que lhe são dissimilares, também, as florestas do Parque Estadual do Rio Doce - MG (CETEC, 1982), que têm mais afinidade florística com a floresta de Linhares - ES (Peixoto \& Gentry, 1990), e a floresta da Ilha do Cardoso (Barros et al., 1991), que tem mais afinidade com a floresta de Ubatuba (Silva \& Leitão-Filho, 1982). Portanto, a comparação florística feita entre as dez florestas por meio de análise de agrupamentos, bem como utilizando as espécies indicadoras de florestas de altitude dentre as espécies comuns entre a Mata da Silvicultura e as demais, revela uma clara influência da flora montana na composição florística da Mata da Silvicultura. As maiores similaridades entre a Mata da Silvicultura e as florestas submontanas ocorreram com as mais meridionais de cada tipologia, Ubatuba (floresta ombrófila densa) e Londrina (floresta estacional semidecidual), assim como houve maior número de espécies indicadoras de florestas de altitude. Esse fato pode ser explicado pela zonação altitudinal que repete a zonação latitudinal, extensamente citada e demonstrada na literatura (Mueller-Dombois \& Ellenberg, 1974; Veloso et al., 1991). Por esse motivo, é provável que sejam encontradas maiores similaridades florísticas entre florestas estacionais semideciduais montanas do Sudeste brasileiro e florestas estacionais semideciduais submontanas do Sul do Brasil do que entre essas florestas submontanas do próprio Sudeste. Se tal fato se confirmar, é mais adequado denominar essas florestas, que seriam zonais e representantes do clímax climático (Mueller-Dombois \& Ellenberg, 1974), como florestas estacionais semideciduais subtropicais. Então, as espécies indicadoras de florestas de altitude seriam denominadas, mais adequadamente, como espécies indicadoras de florestas subtropicais.

A maior constância das espécies consideradas indicadoras de altitude do Sudeste do Brasil é atribuída à ação do clima encontrado a partir de determinada altitude. Essa altitude é considerada como sendo de $750 \mathrm{~m}$, pela demonstração feita por Torres et al. (no prelo) na discriminação entre florestas montanas e submontanas do Estado de São Paulo. Estando as altitudes da Mata da Silvicultura em torno dos $680 \mathrm{~m}$, evidencia-se que a altitude limítrofe pode não ser de $750 \mathrm{~m}$ em florestas de outros Estados, devendo ser consideradas diferenças latitudinais, face de exposição de encostas, distância do Oceano Atlântico e outros fatores regionais que sejam determinantes do clima. Para as florestas da Zona da Mata de Minas Gerais, as altitudes acima de $650 \mathrm{~m}$ parecem ser suficientes para que haja ocorrência desse tipo florestal montano. Veloso et al. (1991) consideraram as altitudes acima de $500 \mathrm{~m}$ determinantes das florestas estacionais semideciduais montanas nessa região.

A análise de agrupamentos é coerente com o número de espécies indicadoras de florestas de altitude em comum entre a Mata da Silvicultura e outras florestas. É interessante que sejam realizados esforços para aumentar essa lista de espécies indicadoras de florestas de altitude, bem como de outros tipos florestais ou vegetações. Essas listas de espécies devem servir como uma informação adicional, sempre levando em consideração o conjunto florístico completo.

\section{CONCLUSÕES}

A Mata da Silvicultura é uma floresta estacional semidecidual semelhante àquelas do interior do Estado de São Paulo, considerando as principais famílias em número de espécies.

Apesar da pequena área que ocupa, a Mata da Silvicultura possui composição florística de espécies arbóreas representativa da flora florestal do norte da Zona da Mata de Minas Gerais.

As maiores altitudes em florestas do Sudeste brasileiro determinaram as maiores similaridades florísticas com a Mata da Silvicultura, enquanto as menores distâncias não foram determinantes de maiores similaridades florísticas a essa floresta.

As florestas de altitude do sul de Minas Gerais e do interior de São Paulo são as de composição florística arbórea mais similar à da Mata da Silvicultura, dentre as florestas comparadas.

As florestas das regiões próximas ao litoral atlântico têm as floras arbóreas mais dissimilares à da Mata da 
Silvicultura, dentre todas as comparadas no Sudeste brasileiro.

Há indícios para que se levante a hipótese de que a similaridade florística entre as florestas estacionais semideciduais de altitude do Sudeste brasileiro e as florestas estacionais semideciduais submontanas aumente conforme aumenta a latitude dessas últimas florestas.

\section{REFERÊNCIAS BIBLIOGRÁFICAS}

ALMEIDA, D. S.; SOUZA, A. L. Florística e estrutura de um fragmento de Floresta Atlântica no município de Juiz de Fora, Minas Gerais. Revista Árvore, v. 21 p. 221-230, 1997.

BARROS, F. et al. Flora fanerogâmica da Ilha do Cardoso - Caracterização geral da vegetação e listagem das espécies ocorrentes. São Paulo: Instituto de Botânica, 1991. $184 \mathrm{p}$.

BROWER, J. E.; ZAR, J. H. Field and laboratory methods for general ecology. 2.ed. Iowa: Wm. C. Brown Company, 1984. 226 p.

CAVASSAN, O.; CESAR, O; MARTINS, F. R.

Fitossociologia da vegetação arbórea da Reserva Estadual de Bauru, Estado de São Paulo. Revista Brasileira de Botânica, v. 7 p. 91-106, 1984.

CENTRO TECNOLÓGICO DE MINAS GERAIS CETEC. Levantamento da vegetação do Parque Estadual do Rio Doce. Belo Horizonte: 1982. 150 p.

COMISSÃO GEOGRÁFICA E GEOLÓGICA DE MINAS GERAIS. Viçosa. Folha no 25 N1E3. Belo Horizonte: 1930. 1 mapa.

CRONQUIST, A. The evolution and classification of flowering plants. New York: The New York Botanical Garden, 1988. 555 p.

DEPARTAMENTO NACIONAL DE METEOROLOGIA. Normais climatológicas (1961 - 1990). Brasília: 1992. $84 \mathrm{p}$.

GIBBS, P. E.; LEITÃO-FILHO, H. F. Floristic composition of an area of gallery forest near Mogi Guaçu, state of São Paulo, SE Brazil. Revista Brasileira de Botânica, v. 1 n. 2 p. $151-156,1978$.
GOLFARI, L. Zoneamento ecológico do Estado de Minas Gerais. Belo Horizonte: Centro de Pesquisa Florestal da Região do Cerrado, 1975. 65 p.

LEITÃO-FILHO, H. F. Aspectos taxonômicos das florestas do Estado de São Paulo. Silvicultura em São Paulo, v. 16 p. 197-206, 1982.

MARISCAL-FLORES, E. J. Potencial produtivo e alternativas de manejo sustentável de um fragmento de Mata Atlântica secundária, Município de Viçosa, Minas Gerais. Viçosa: Universidade Federal de Viçosa, 1993. 165 p. Dissertação (Mestrado em Ciência Florestal) Universidade Federal de Viçosa, 1993.

MEIRA-NETO, J. A. A. et al. Composição florística da floresta semidecídua de altitude do Parque Municipal da Grota Funda (Atibaia, Estado de São Paulo). Acta Botanica Brasilica, v. 3 p. 51-74, 1989.

MEIRA-NETO, J. A. A. et al. Estrutura de uma floresta estacional semidecidual aluvial em área de influência da Usina Hidrelétrica de Pilar, Ponte Nova, Zona da Mata de Minas Gerais. Revista Árvore, v. 21, n. 2, p. 213-219, 1997a.

MEIRA-NETO, J. A. A. et al. Estrutura de uma floresta estacional semidecidual submontana em área de influência da Usina Hidrelétrica de Pilar, Ponte Nova, Zona da Mata de Minas Gerais. Revista Árvore, v. 21, n. 3, p. 337-344, 1997b.

MEIRA-NETO, J. A. A. et al. Estrutura de uma floresta estacional semidecidual insular em área de influência da Usina Hidrelétrica de Pilar, Ponte Nova, Zona da Mata de Minas Gerais. Revista Árvore, v. 21, n. 4, p. 493-500, $1997 \mathrm{c}$.

MEIRA-NETO, J. A. A. et al. Estrutura de uma floresta estacional semidecidual insular em área de influência da Usina Hidrelétrica de Pilar, Guaraciaba, Zona da Mata de Minas Gerais. Revista Árvore, v. 22, n. 2, p. 179-184. 1998.

MEIRA-NETO, J. A. A.; MARTINS, F. R. Estrutura da Mata da Silvicultura, uma floresta estacional semidecidual montana no município de Viçosa-MG. Revista Árvore, v. 24 , n. 2, p. 151-160, 2000.

MOTA, A. L. P. Estudo dendrológico na Mata da Casca d'Anta - Parque Nacional da Serra da Canastra, MG. Viçosa, MG: Universidade Federal de Viçosa: 1984. 183 p. Dissertação (Mestrado em Ciência Florestal) - Universidade Federal de Viçosa, 1984.

R. Árvore, Viçosa-MG, v.26, n.4, p.437-446, 2002 
MUELlER-DOMBOIS, D.; ELlENBERG, H. Aims and methods of vegetation ecology. New York: John Wiley \& Sons, 1974. $547 \mathrm{p}$.

OLIVEIRA-FILHO, A. T.; MACHADO, J. N. M. Composição Florística de uma floresta semidecídua montana, na Serra de São José, Tiradentes, Minas Gerais. Acta Botanica Brasilica, v. 7, p. 71-88, 1993.

OLIVEIRA-FILHO, A. T. et al. Comparison of the woody flora and soils of six areas of montane semideciduous forest in southern Minas Gerais, Brazil. Edinburgh Journal of Botany, v. 51, p. 355-89, 1994.

PEIXOTO, A. L.; GENTRY, A. A diversidade e composição florística da mata de tabuleiro na Reserva Florestal de Linhares (Espírito Santo, Brasil). Revista Brasileira de Botânica, v. 13, p. 19-25, 1990.

RODRIGUES, R. R. et al. Estudo florístico e fitossociológico em um gradiente altitudinal de mata estacional mesófila semidecídua na Serra do Japi, Jundiaí. Revista Brasileira de Botânica, v. 12, p. 71-84, 1989.

SALIS, S. M. Composição florística e estrutura de um remanescente de mata ciliar do Rio Jacaré-Pepira, Brotas, SP. Campinas: Universidade de Campinas, 1990. 111 p. Dissertação (Mestrado em Ciência Florestal) Universidade de Campinas, 1990.

SCHIAVINI, I. Estrutura das comunidades arbóreas de mata de galeria da Estação Ecológica do Panga. Campinas: Universidade de Campinas, 1992. 139 p. Tese (Doutorado em Ciência Florestal) - Universidade de Campinas, 1992.

SIEGEL, S. Estatística não paramétrica para as ciências do comportamento. São Paulo: McGraw-Hill do Brasil, 1975. $350 \mathrm{p}$.

SILVA, A. F. Composição florística e estrutura fitossociológica do Estrato Arbóreo da Reserva Florestal Professor Augusto Ruschi, São José dos Campos, SP. Campinas: Universidade de Campinas, 1989. 163 p. Tese (Doutorado em Ciência Florestal) - Universidade Federal de Campinas, 1989.
SILVA, A. F.; LEITÃO FILHO, H. F. Composição florística e estrutura de um trecho de mata atlântica de encosta no município de Ubatuba (São Paulo, Brasil). Revista Brasileira de Botânica, v. 5, p. 55-94, 1982.

SIQUEIRA, M. F. Análise florística e ordenação de espécies arbóreas da Mata Atlântica através de dados binários. Campinas: Universidade de Campinas, 1994. 143 p. Dissertação (Mestrado em Ciência Florestal) Universidade de Campinas, 1994.

SNEATH, P. H.; SOKAL, R. R. Numerical taxonomy. San Francisco: W. H. Freeman and Company, 1973. 573 p.

SOARES-SILVA, L. H.; BARROSO, G. M. Fitossociologia do estrato arbóreo da floresta na porção norte do Parque Estadual da Mata dos Godoy, Londrina-PR, Brasil. In: CONGRESSO DA SOCIEDADE BOTÂNICA DE SÃO PAULO, 8., 1992, Campinas Anais... São Paulo: Sociedade Botânica de São Paulo, 1992. p.101-112.

TORRES, R. B. Estudos florísticos em mata secundária da Estação Ecológica de Angatuba, Angatuba (São Paulo). Campinas: Universidade de Campinas, 1989. 231 p. Dissertação (Mestrado em Ciências Biológicas) Universidade de Campinas, 1989.

TORRES, R. B.; MARTINS, F. R.; KINOSHITA-GOUVEA, L. S. Climate, soil and tree flora relationships in forests in the state of São Paulo, southeastern Brazil. Revista Brasileira de Botânica. No prelo.

VALVERDE, O. Estudo regional da Zona da Mata de Minas Gerais. Revista Brasileira de Geografia, v. 20, n. 1, p. 1-82, 1958 .

VELOSO, H. P.; RANGEL-FILHO, A. L. R.; LIMA, J. C. A. Classificação da vegetação brasileira, adaptada a um sistema universal. Rio de Janeiro: IBGE. 1991. $124 \mathrm{p}$.

VOLPATO, M. M. L. Regeneração natural em uma floresta secundária no domínio de Mata Atlântica: uma análise fitossociológica. Viçosa, MG: Universidade Federal de Viçosa, 1994. 123 p. Dissertação (Mestrado em Ciência Florestal) - Universidade Federal de Viçosa, 1994. 